\title{
Indicator System and Assessment of Social Stability Risk in Road Construction
}

\author{
Chengjie JIANG ${ }^{1,2, *}$ \\ ${ }^{1}$ Division of Development and Cooperation, Zhejiang \\ College of Construction, Hangzhou, 311231, China \\ ${ }^{2}$ School of Insurance and Economics, University of \\ International Business and Economics, Beijing, 100029, \\ China \\ e-mail: 735195858@qq.com \\ *Corresponding author \\ Honglei WANG \\ Zhejiang Wuzhou Engineering Project Management Co. \\ Ltd., Hangzhou, 310053, China
}

\author{
Enhai CHAI \\ Zhejiang Wuzhou Engineering Project Management Co. \\ Ltd., Hangzhou, 310053, China
}

\begin{abstract}
By taking Jiande-Jiangshan Road (Zhejiang provincial road S316) as an example, the author indentifies the factors of social stability risk through the hierarchical holographic modeling method (HMM) and formulates single factor risk indicator system of social stability risk in road construction projects. The overall initial risk grade of the project is confirmed by means of weight allocation and superposition and consolidation of the single factor risk, qualitative and quantitative analysis as well as expertise. The author hopes that this essay and the corresponding measures and countermeasures put forward in this essay may be conducive to a further improvement in the social stability risk assessment mechanism for road construction projects.
\end{abstract}

Keywords-Social Stability Risk; Road Construction; Indicator System; Risk Assessment

\section{INTRODUCTION}

In order to decrease social contradictions and disputes as well as reduce social stability risk in project construction and operation, China International Engineering Consulting Corporation (CIECC) introduced, for the first time in China, the social risk analysis into social assessment system in its publication of Guideline for Social Assessment of Investment Project in China in 2004. In fact, public participation has been practiced in China's international aid projects or items for the said purpose for many years. [1] Jianhui Cai and Qi Ling put forward in their study of the social assessment of road projects that projects social assessment should, in general, considers the influence of production, distribution, exchange and consumption and hereof analyze its influence in the construction of road projects. [2]

The recent years has witnessed the emergence of some social contradictions arising from the construction and operation of road project, which has led to emergencies such as mass incidents at times. Therefore, attention has to be paid to the level of mutual adaptation between road project and the local social development, to the feasibility of road project and to the sustainable harmonic development. National Development and Reform Commission of the People's Republic of China (NDRC) formulated The Interim Measures on Risk Assessment of
Major Fixed Asset in Investment Projects and Social Stability in August 2012 for the purpose of building and standardizing assessment mechanism of the social stability risk in major investment projects of fixed assets, preventing social risk, effectively reducing social contradiction and maintaining social stability. Analysis of the social stability risk in road projects feasibility phase is of great significance to the project implementation. It should take the maintaining of the masses' fundamental interests as the starting point and objective, fully considers the legal rights and interests as well as reasonable demands of both citizens and project implementers, guards against and reduces social contradiction, and prevents and dissolves the social stability risk from the very beginning of the project.

\section{RISK SURVEY}

\section{A. Project Overview}

Jiande-Jiangshan Road (Zhejiang provincial road S316) is an important route of the general national and provincial highway in Zhejiang province. It has a land occupation of $78.0257 \mathrm{ha}$ and an overall length of $23.265 \mathrm{~km}$, including a newly constructed $14.494 \mathrm{~km}$ of mainline and branch and a renovate $8.771 \mathrm{~km}$ of logistics road. The road has a new construction and reconstruction of bituminous concrete pavement of $283.127 \mathrm{~km} 2$ and $177.638 \mathrm{~km} 2$ respectively, 6 large and medium sized bridges with a length of $1498.3 \mathrm{~m}$, 4 small bridges with a length of $104 \mathrm{~m}, 43$ culverts and 19 at-grade intersections. The technical standard for A roads specified in Technical Standard of Highway Engineering (JTG B01-2003) has been applied in the construction of the road with two-way four-lane, a roadbed width of $26 \mathrm{~m}$, design speed of $80 \mathrm{~km} / \mathrm{h}$ and the bridge motor vehicle loading at the level of A roads.

\section{B. Survey Description}

Based upon the on-the-spot survey along the project line and the collection of opinions of the community and masses that live in the project site, it is determined that the stakeholders in respect of social stability of the project should include the right and interest holders of residences, regardless of their being relocated according to plan, from which potential risks may be involved and exert influence 
on the project. The assessment team of the project organized 7 conversaziones one after another. Participants attending these conversaziones are cadres and villager representatives in towns and villages from Garden Community, Huangjia Community, Shishi Town, Shuanggang Community, Hangbu Town, Henglu Sub-district Office, Donggang Community as well as representatives from Quzhou Traffic Design Co., Ltd. The assessment team sent out questionnaires to them. Specifically, the assessment team sent out a total of 100 questionnaires to the villager representatives who attended the conversaziones and reclaimed 100.

\section{Survey Result}

(1) Project Familiarity The statistics of the questionnaires indicates that those who know very well about, know of partial information, only heard of and know nothing about the project account for $11 \%, 65 \%$, $19 \%$ and $5 \%$ of the respondents respectively. Hence it is suggested that popularization of the project should be strengthened in the next phase.

(2) Project Support $90 \%$ of the respondents expressed their supportive attitudes, $5 \%$ of them shown their indifferences, while $2 \%$ of them indicated their nonsupport to the project, which shows that there is a good social foundation for the project advancement. In addition, $55 \%$ of the respondents believe that their livelihoods and travelling will be greatly improved upon completion of the project, and still $32 \%$ of them think that improvement might be general, which indicates there is a sound masses base for project construction that significantly improves the livelihoods and travelling of the villagers along the road.

(3) Masses Concerns: In respect of specific concerns, the top two concerns are the influences of the project on eco-environment and transportation with equal $36 \%$ of the respondents, which is followed by the influences on safety and sanitation with $21 \%$ of the respondents, and it is thus suggested that good works should be done in terms of environmental protection and transportation arrangement. In terms of the influence of the project on transportation, $63 \%$ of respondents believe the regional transportation will be greatly improved upon completion the project, and $32 \%$ of respondents think that improvement might be general, which indicates the project construction brings a sound social benefit by significantly improving the regional transportation. In regards to commencement of the project, $81 \%$ of the respondents expect that the project be commenced as early as possible, while those who abstain, reserve, and are not inclined to support it accounts for $8 \%, 4 \%$ and only $1 \%$ respectively, which shows that the majority of villagers along the road support the project construction.

\section{RISK IDENTIFICATION AND ANALYSIS}

\section{A. HHM Analysis of Social Stability Risk}

As a comprehensive ideology and methodology, HMM aims to capture and show the internal different feature and essence of one system. It is applied to use different hierarchic models in order to seek the understanding of one and the same theme from different aspects, and then understands the integrity. Since there are usually many risk evaluation indicators involved in major engineering projects, it is very important to have a reasonable controlling of the scale of assessment indicator system. Otherwise, it will be difficult to achieve an accurate reflection of features of major engineering project in the event of insufficient indicators, or easy to cover up the differentiation among risks in the case of excessive indicators. Therefore, the number of evaluation indicator must be appropriate in this regard. [3]

\section{B. Single Factor Risk Analysis}

Based on the source of risk, the social stability risk of engineering project can be divided into 2 categories, namely, project internal and external factors, which consist of 9 sub-categories including economic factors, land acquisition and resettlement of inhabitant factors, project external environmental factors, community relations factors, eco-environmental factors, project features, stakeholders factors, engineering organization and management, and technical factors. All these factors constitute the HMM framework of social stability risk involved in major engineering project. [4] According to onsite survey, discussion and interview with representatives from township and village along the road, and other information, the concrete project construction and HMM analysis, the above 9 sub-categories can be compressed into 5 major risk factors, namely, technical factors, land acquisition and resettlement of inhabitant factors, community relations factors, project external environmental factors and eco-environmental factors. The detailed analysis is as follows:

(1) Technical Factors: risks resulted from project engineering plan can be shown in 4 aspects typically: a. if there is a design defect in terms of road drainage and such road is put into operation in heavy rain weather after project completion, there will be severe road ponding which will result in urban inland inundation due to drainage pipelines malfunction or capacity shortage; $b$. Given there is a partial superposition between Hangbu Town section of the project and the local channel, the villagers worry about the road construction may lead to flow retarding in the channel and a local flood as a result; c. Problems of intersection and joining treatment among the project, the current roads and the planning roads, joining of the current pipelines and reservation of the planning pipelines; $d$. the high voltage line's' impact on the project as it locates in the middle of 3 high voltage corridor belts with its lines pass through.

(2) Land Acquisition and Resettlement of Inhabitant Factors: risks of land acquisition, demolition and compensation of the project mainly occur in the following 3 aspects: a. Due to the problems of plantation and irrigation in farmland in the dead corner area after the completion of Kengxi Bridge, villagers suggest that the affected farmland be expropriated along with all the others; b. Compensation for land acquisition and demolition out of the Road construction must be conducted reasonably and farmers' loss of farmland and their pension insurance shall be taken into consideration as well; c. In the process of land acquisition and demolition, masses in different areas may strive to keep up with each other which may result in the phenomenon of mood fluctuation and anger that may be trigger of risks.

(3) Community Relations Factors: contradictions or conflicts may occur due to the lack of timely completion 
of land borrowing or road borrowing procedures, lack of communication and coordination mechanism with the locals, or masses' doubts out of inadequate popularization. It can be shown in 3 respects: a. It is necessary to complete the relevant safety precautions for the intersection between the Road and village roads for fear of causing threat to masses; b. It is necessary to set deceleration strip and distinct school warning sign when the Road passes the Garden Primary School, and the traffic lights in front of the School shall be reasonably necessary for the pupils and their parents to pass in school's rush hour; 3. Due to the occurrence of several road accidents in Fengjia Overpass section in the National Highway 320 in the past few years, it is suggested to dismantle the Overpass and replace it with roundabout or level crossing signal light management at the time of branch line construction of the project.

(4) Project External Environmental Factors: Standpoint and orientation of media and internet speech can have great impact on masses. Therefore, it is necessary to take into enough consideration the standpoint of a report as well as its amplification of pros and cons of the major engineering project because they can guide behaviors of the mass to huge extent.

(5) Eco-environmental Factors: With the development of social economy and rapid increase of urban vehicle holdings, the number of vehicle on the road has been continuously increased. Apart from the high noises, vibration of vehicle traffic causes buildings crack on both sides of the road. Also, the traffic noises and vibration can cause certain impacts on the precise instrument sensitive to vibration happened, on devices and buildings located and residents live in the vicinity. Pedestrian and road sanitation workers throw household garbage on roadside, overhead bridges, watercourses, green belts, which exerted influence on the environmental sanitation and landscape environment of the villages alongside.

\section{Evaluation Criteria}

Risk probability-impact matrix will be applied to analyze the major risks of the project as well as to determine their risk grade. Specifically, risk probability-impact matrix is mainly used to analyze concrete risk point and evaluate the risk grade of the risk point. In the matrix, the probability of occurrence of a risk factor is the abscissa, while the impact of occurrence of a risk factor is the ordinate.

According to the risk probability-impact matrix, the influence of a risk includes 5 levels, namely, severe, high, moderate, small and negligible; and the probability of occurrence of a risk also includes 5 grades, namely, very high, high, moderate, low and very low. A risk point, after combination with different risk influence and probability, may be divided into 5 levels, namely, major risk, high risk, general risk, low risk and tiny risk. In order to analyze the probability of occurrence of the above-mentioned risk factors and the influence of a risk event, the probable risk events is analyzed by experienced experts through Delphi Method on the basis of the former single factor risk assessment criteria. The risk degree of a single factor is eventually determined by means of obtaining the single risk's probability of occurrence and scope of influence according to the analysis of expertise as well as the analysis in comparison with the risk probability-impact matrix. In the practice, we ask for expertise one by one, collect and send it to experts for analysis and raise new arguments and opinions in this process. Gradually, a consensus is reached among experts after such a multiple replication.

\section{Risk Grade Analysis}

Based on the project feature and the confirmed single factor initial risk grade, the social stability risk assessment team obtains the risk assessment of the entire project by means of weight allocation and superposition of the single factor, qualitative and quantitative analysis as well as expertise. The overall initial risk grade of the project may be confirmed in line with risk weight and degree of risk of the single factor.

Based on China's national regulations on comprehensive assessment methods of risks, the degree of risk has been adjusted after the implementation of effective precautions. According to calculation, the final risk indicator is 0.18 , which shows that the degree of risk of the project is low.

\section{RisK PREVENTION MEASURES}

The following risk prevention measures are proposed reasonably and feasibly on the basis of the overall objective of the project construction with the principle of improving the capability of risk control and lowering the potential hazard through risk reduction.

(1) To standardize procedures in each phase to ensure that relevant laws and regulations be satisfied in project construction, maintain publicity and transparency of procedures of project construction, popularize validity and scientificity of the project through diversified forms, and strengthen publicity and transparency of project examination and approval to eliminate masses' query of validity and approval of the project.

(2) To strictly carry out overall analytic demonstration and comprehensive assessment of engineering proposals. The designing of engineering proposals should be technically advanced and feasible, economically reasonable and effective. It is necessary to strictly conduct overall analytic demonstration and comprehensive assessment in terms of selection of solution. Proposals design shall reduce as far as possible the impact on livelihood of masses alongside and try to satisfy their reasonable demands. A detailed plan of public participation shall be formulated in the period of proposal's publicity and survey. In order to find the masses' demand scientifically and reasonably, it is necessary to design a questionnaire for public participation so that their opinions and suggestions towards the project construction be reflected objectively and overall.

(3) To formulate measures and social stability control preplanning for complaint and petition risk. It is necessary to strengthen positive popularization and guidance of the engineering, pay close attention to reasons of removal and relocation proposed by residents and apply to corresponding mitigation measures as far as possible, enhance communication in the implementation to ease masses' unstable mood, and formulate the contingency plan for maintenance of social stability.

(4) To strictly carry out environmental influence measures in construction period and make just 
compensation for damages out of construction; meticulously design the organization plan for construction, strengthen communication with communities and masses along the road in the construction and optimize the construction plan in time; and ensure a convenient and safe passing, driving and travelling to residents.

(5) To enhance the positive popularization to guide media in the right direction. Based on compliance with laws and regulations, it is necessary to strengthen the positive popularization of the project to increase masses' inclusiveness while lower the risk of petition. In order to show full respect for the masses, it is necessary to convoke project briefing in front of the local government and residents representatives prior to public announcement of the project plan, provide uniform answers them in terms of the project plan and policy requirements, and popularize the project's positive impact on the local social and economic development. Moreover, it is necessary to pay real time and high attention to public sentiments, release authoritative information in time to build a sound public opinion environment by means of guiding and influencing the media.

(6) To effectively communicate with the masses along the road to ease the relations with them. It is necessary to attach great importance to the means of communication because it plays an important role in the project management. Besides, right ways of communication can effectively coordinate external relations for the project. In the process of project construction, the construction organization and the property owner unit should know well about local masses' reaction to the project construction through their active communication with them, close attention to what villager concerns from such channels as bulletin boards and mailboxes on the villages and sub-district office along the road. In order to avoid tension for lack of communication with them, it is necessary to make explanation or take relevant measures in time for the feedbacks and opinions of the masses alongside.

(7) To strengthen road operation management to ensure the safety and sanitary environment along the lines, define such responsibilities as garbage collection and disposal along the road in the operation, and handle garbage huddle phenomena through collection in time and centralized dispose. It is necessary to carry out regular and proper clean-up of garbage to completely eliminate garbage pollution by getting rid of garbage stockpile alongside and dealing with huddle phenomena.

\section{SUMMARY}

Social stability risk assessment can be used to ensure the smooth implementation of a project by means of optimizing engineering plan, determining the risk control point as well as proposing corresponding measures and solution. Social stability risk assessment for large projects can discerns and resolves social stability risks from the source of project construction, avoids waste of project funds and other resources out of social stability risk events. Meanwhile, social stability risk assessment for large projects, to a large extent, safeguards the interests of stakeholders, with vulnerable groups in particular, may win support from stakeholders including the public. As a result, it can ensure a smooth progress of the project construction and improves its efficiency at the same time.

Social stability risk indicator system and assessment for large projects are of great significance to the promotion of social harmony and stability in China. Mass incidents have been on the ascending in China in recent years, which have seriously influenced stability of China's State and society. Therefore, social stability risk assessment for large projects is not only a significant initiative for enhancement of social management innovation and promotion of social harmony and stability, but also an important part of assessment of the project social impact.

\section{ACKNOWLEDGEMENT}

This essay is funded by or listed in several projects or programs, which include or is the phasic research result of "Engineering Insurance Development Strategy in the Background of Urban-rural Integration" (Project Approval No. 2016-R2-007) under the title of Science and Technology Project 2016 funded by Ministry of Housing and Urban- Rural Development of the People's Republic of China (MOHURD); "Investment and Financing Analysis and Risk Control of Infrastructure Construction Projects"(Project Approval No.17NDJC245YB) under the title of planning project 2017 of Zhejiang provincial philosophy and social science; a project for the sponsorship of engineer working at institution of higher learning in Zhejiang province to make visit at China's institutions of higher learning; and the phasic research result of "Regional Differentiation of New-type Urbanization-based Engineering Insurance " (Project Approval No. 2015K82) under the title of scientific research project 2015 funded by Department of Housing and Urban- Rural Development of Zhejiang Province.

\section{REFERENCES}

[1] China International Engineering Consulting Corporation, Guideline for Social Assessment of Investment Project in China [M], Beijing, China Planning Press, 2004.

[2] Jianhui Cai, Qi Ling, Social Assessment of Road Construction Project, Journal of Fuzhou University (Social Science), 1999.

[3] LinYang, E'xiang Luo, Study on Social Risk Assessment Indicator System for Large Project, Science-Technology and Management, 2010.

[4] Zhenting Zhao, Study on Social Stability Risk Indicator System and Assessment for Large Projects, Master Degree Thesis, Southwest Jiaotong University, 2014. 